\title{
Drugs as important factors causing allergies
}

\author{
Wioletta A. Żukiewicz-Sobczak ${ }^{1}$, Paula Wróblewska², Piotr Adamczuk², Jacek Zwoliński², Anna Oniszczuk², \\ Paulina Wojtyła-Buciora ${ }^{4}$, Wojciech Silny ${ }^{5}$
}

1Pope John Paul II State School of Higher Education, Biala Podlaska, Poland

Rector of the School: Prof. Józef Bergier

${ }^{2}$ Department of Allergology and Environmental Hazards, Institute of Rural Health, Lublin, Poland

Head of the Department: Wioletta A. Żukiewicz-Sobczak PhD

${ }^{3}$ Department of Inorganic Chemistry, Medical University of Lublin, Lublin, Poland

Head of the Department: Prof. Monika Waksmundzka-Hajnos

${ }^{4}$ Department of Hygiene, Poznan University of Medical Sciences, Poznan, Poland

Head of the Department: Prof. Jerzy Marcinkowski MD, PhD

${ }^{5}$ Greater Allergy and Dermatology Center "Art Clinic", Poznan, Poland

Head of the Department: Paweł Silny MD, PhD

Postep Derm Alergol 2015; XXXII (5): 388-392

DOI: $10.5114 / p d i a .2014 .44021$

\begin{abstract}
Medications can cause many adverse reactions, both non-immunologic and immunologic ones. Allergies can take many forms, allergic reactions include all types of reactions according to Gell and Coombs. Typically, allergic reactions to drugs are manifested by skin lesions such as maculopapular rash or urticaria and life-threatening systemic reactions such as anaphylaxis. Allergy to drugs is diagnosed based on medical history and a number of specific tests: skin tests, blood tests. In diagnosing the causes of anaphylaxis, the basophil activation test is used to exclude false negative and false positive results of skin tests and specific IgE levels. Allergic reactions to medications usually resolve themselves after discontinuation of the drug. Sometimes in the treatment anti-allergic drugs are used to inhibit the development of skin lesions. After observing any signs of drug allergy it is important to accurately diagnose the cause, since the subsequent exposure to the drug may lead to a strong anaphylactic reaction and consequently death.
\end{abstract}

Key words: allergy, allergic diseases, drugs, antibiotics.

\section{Introduction}

All data on the incidence of adverse drug reactions are estimated because they do not monitor exactly this phenomenon. It is estimated that adverse effects of drugs are the cause of about $5 \%$ of hospital admissions and occur in 10-20\% of hospitalized patients [1, 2]. Drug hypersensitivity reactions are most common in patients over 50 years of age and $63-70 \%$ of patients suspected of having an allergic reaction to the drugs are women [3]. Allergic reactions induced by drugs are frequently observed in $20-80 \%$ of patients with HIV and about $30 \%$ of cystic fibrosis patients [4].

Frequently observed allergic reactions are especially to $\beta$-lactam antibiotics $[5,6]$. It is estimated that IgEmediated allergy to antibiotics is present in 2-3\% of the general population [7], and $5 \%$ of the population have allergic reactions to penicillin and other $\beta$-lactam $[8,9]$. Skin symptoms, including acute urticaria are frequently observed in patients treated with amoxicillin and ampi- cillin [10]. Systemic anaphylactic reactions are quite rare, and occur on average, from $0.004 \%$ to $0.015 \%$ of the cases, and about $10 \%$ of them are fatal [11].

There is a growing trend to prescribing antibiotic treatments. Analyzing the consumption of antibiotics in European countries, the defined daily dose (DDD) of an antibiotic or DDD per 1000 inhabitants per day is used. The results of the statistical analyses indicate that the highest consumption of antibiotics occurs in the countries of southern and eastern Europe [12-14]. Frequent antibiotic treatment is a major factor leading to the development of microorganisms' resistance to antibiotics. In Greece, where one of the highest rates of DDD is observed, also the highest rate of bacterial resistance to antibiotics is observed [15].

Many researchers have shown an association between antibiotic use in children and disorders of the immune system and the occurrence of atopic diseases. One of many large cohort studies showed that exposure of

Address for correspondence: Prof. Wioletta A. Żukiewicz-Sobczak HSc, PhD, Pope John Paul II State School of Higher Education, 95/97 Sidorska St, 21-500 Biala Podlaska, Poland, phone: +48 698143 743, e-mail: wiola.zukiewiczsobczak@gmail.com Received: 10.04.2014, accepted: 29.04.2014. 
the fetus to maternal use of antibiotics increases the risk of asthma and eczema in children $[16,17]$. Other studies have shown that the use of antibiotics in infants in the first months of life predisposes to the development of asthma and allergies in children aged $6-7$ years $[18,19]$.

\section{Diversity of allergic reactions caused by drugs}

Adverse reactions to drugs can be divided into nonimmunologic and immunologic reactions. Unrelated to the functioning of the immune system, the reactions of intolerance, pseudoallergy, and idiosyncrasy are usually caused by non-steroidal anti-inflammatory drugs, radiological contrast agents, opiates, and local anesthetics. Allergic reactions are more unpredictable and the immune system plays an important role in their pathogenesis [20].

Allergic reactions to drugs can manifest as organ or systemic reactions. Examples of systemic allergic reactions are anaphylaxis, serum sickness, various types of rash with eosinophilia and systemic symptoms (DRESS, drug rash with eosinophilia and systemic symptoms) [20, 21].

Frequent and prolonged use of the drug, its inadequate cleaning or content of additives and preservatives favor the development of drug allergy. In patients with atopy, no instances of a higher incidence of allergic reactions to drugs were observed, but the course of an anaphylactic reaction is considerably heavier than in non-atopic individuals $[5,6]$. Anaphylaxis reactions most commonly are observed after administration of: aspirin, non-steroidal anti-inflammatory agents, intravenous contrast agents and $\beta$-lactam antibiotics [20].

Allergies to drugs can take many forms as these reactions include all types of reactions according to Gell and Coombs (Table 1), while the worst are immediate reactions involving IgE antibodies [22].

\section{Drugs as allergens}

Macromolecular substances such as hormones, enzymes or sera are most allergenic. Only a few drugs (formulations of proteins, peptides) are complete allergens. Most drugs are small molecule substances, which naturally reduces their ability to induce an immune response. Such particles often have the ability to connect to proteins purchasing immunogenic properties. These particles then form haptens. More often metabolites of the drug are reactive, and referred to as a pro-hapten
$[7,23]$. Examples of complete antigens are insulin and other hormones, sera, and vaccines. Other haptens are $\beta$-lactam antibiotics, and among prohaptens: sulfonamides, phenacetin, and phenytoin [23].

\section{$\beta$-Lactam antibiotics: the most common allergens among drugs}

Most symptoms of allergies are produced by $\beta$-lactam antibiotics. Bactericidal action of these antibiotics involves the inhibition of bacterial cell wall synthesis. This action is based on the inhibition of transpeptidase, an enzyme necessary for the synthesis of peptidoglycan (murein), which is the basic component of the bacterial cell wall. Opening peptidoglycan strands during cell division leads to the bacteriolysis, which means that the $\beta$-lactam antibiotics kill cells only during division. The antibiotics of this group do not show bactericidal activity against bacteria devoid of cell wall such as the genus Mycoplasma or intracellularly growing Legionella, or Chlamydia [24].

$\beta$-Lactam antibiotics include: penicillins, cephalosporins, carbapenems and monobactams. According to numerous studies, this group is the most commonly prescribed antibiotics in medicine. This is due to the wide range, high efficiency and safety of use, despite inducing allergy in about $5-10 \%$ of patients treated [24].

Allergic reactions caused by $\beta$-lactam antibiotics bind to their chemical structure. The source of haptens is an unstable $\beta$-lactam ring to which proteins bind to form penicilloyl epitopes (called "major determinant") responsible for the allergy to penicillin. Another source of allergens is pro-haptens - penicillin breakdown products such as penicilloic acid, penicilloate, penilloate. Clinical studies show that this determinant is less likely to be responsible for anaphylaxis reactions. Penicilloyl and nonpenicilloyl determinants are responsible for IgE-mediated allergies and for the occurrence of cross-reactions of various penicillins. In contrast, side chains of $\beta$-lactam rings are responsible for IgE-independent allergies, and crossreactions to $\beta$-lactam antibiotics $[23,25]$.

In the case of allergy to $\beta$-lactam antibiotics, crossreactions to penicillin, ampicillin and amoxicillin were often observed. Often the skin tests do not confirm the allergy to the antibiotic, even though the patient has symptoms after administration. Patients with reactions observed immediately after administration of amoxicillin

Table 1. Symptoms of allergies to medicines according to Gell and Coombs [20, 22]

\begin{tabular}{lcr}
\hline $\begin{array}{l}\text { Gell and Coombs } \\
\text { reaction type }\end{array}$ & Time to onset of response & Examples of symptoms \\
\hline I & Up to 10-30 min & Anaphylactic shock, asthmatic attack, angioedema, some urticaria \\
\hline II & After 50 min, but usually after 3 days & Erythema after penicillin, hemolytic anemia \\
\hline III & After 3-5 days & Some urticaria, drug fever, vasculitis, hepatitis \\
\hline IV & After 7 days & Contact dermatitis \\
\hline
\end{tabular}


were characterized by a high risk of hypersensitivity to penicillin and ampicillin [26].

Despite numerous adverse effects associated with the use of $\beta$-lactam antibiotics, it is still a group of antibiotics eagerly used to treat bacterial infections.

\section{Symptoms of allergy to drugs}

Skin symptoms of drug allergy may be caused by almost all of the drugs administered by the oral route [27, 28], but also applied to the skin such as formulations containing salicylic acid [29], macrolides [30] and many other active ingredients [31]. One of the most frequently observed drug-induced changes is allergic maculopapular rash. It is estimated that this rash comprises about $75 \%$ of all allergic reactions caused by drugs [10]. The symptoms of maculopapular rash may occur after taking almost any medication, even in the distant time of application. The clinical picture often resembles measles or rubella [32-34]. Rash symptoms take the form of a number of spots, papules and erythema, often arranged symmetrically on the skin. Maculopapular rash is most commonly observed in the vicinity of the trunk and limbs, and the appearance is often accompanied by a high fever, eosinophilia and severe itching [32, 35]. Rashes tend to spread and infiltration. Changes disappear several days after discontinuation of the drug, and this is accompanied by extensive exfoliation of the epidermis, which may leave discolorations on the skin [31,36]. The drugs that cause the symptoms of rashes include non-steroidal anti-inflammatory drugs, ACE inhibitors, $\beta$-blockers, barbiturates [7, 37, 38] and antibiotics used in the course of respiratory infections [31, 36].

The most serious form of pustules described in recent years is acute generalized exanthematous pustulosis (AGEP) [37]. Its symptoms are generalized erythema for several hours after administration $[39,40]$, and skin changes are associated with fever. Changes localize initially on the face, and then also on the trunk and limbs. Generalized pustular rash is quite a rare disease associated with the presence of antigens HLA-B51, HLA-DR11 and HLA-D9 [41]. Its symptoms usually appear after taking antibiotics ( $\beta$-lactam antibiotics, tetracyclines, macrolides) or other drugs, e.g. furosemide or non-steroidal anti-inflammatory drugs [40, 41].

Another common skin reaction is drug-induced urticaria. Only in 10\% of cases, it has an allergic background, and most often it is caused by penicillins or sulfonamides [11]. Urticaria may be accompanied by systemic allergic anaphylaxis or serum sickness [37]. Pseudoallergic urticaria occurs most frequently after administration of aspirin (acetylsalicylic acid), contrast agents, non-steroidal anti-inflammatory drugs and the symptoms are the same as in the case of allergic urticaria [11]. A symptom of the disease is urticaria with accompanying pruritus. Symptoms usually appear within $36 \mathrm{~h}$ of taking the drug, although after the re- administration of the drug, symptoms may appear after a few minutes. Symptoms of urticaria usually disappear quickly - after several hours [39].

The clinical picture of cutaneous drug reactions is characterized by considerable polymorphism. Various drugs can cause similar or identical lesions, and the same drugs cause complications with a different clinical picture [41]. Drug-induced skin lesions are usually mild, and the symptoms disappear spontaneously after discontinuation of the drug. Severe skin lesions include: skin necrosis, epidermolysis bullosa, swelling of the face or tongue and the co-appearance of systemic symptoms [20, 27].

Systemic reactions are usually manifested by the anaphylactic reaction. It is the most dangerous drug-induced reaction developing within a few minutes after the repeated administration of the drug [34], and rarely after the first dose [42]. Symptoms of anaphylactic reaction can include lower blood pressure, tachycardia, chest pain, and seizures. These symptoms may be accompanied by other symptoms such as abdominal pain, bronchospasm, and even cardio-respiratory failure [7]. Sometimes an anaphylactic reaction is also accompanied by cutaneous erythema or edema [40]. Anaphylaxis symptoms are most commonly caused by antibiotics - penicillins, nonsteroidal anti-inflammatory drugs, ACE inhibitors, radiographic contrast agents, and muscle relaxants [1, 39, 40, 42]. In the United States, $75 \%$ of all anaphylactic shock cases are caused by penicillin [1].

\section{Diagnosis of drug allergy}

Diagnosis of drug allergy is quite complicated and usually begins with an extensive medical history. The interview should be completed with all the necessary detailed tests such as: complete blood count with eosinophilia, the concentration of IgG, IgM, and the concentration of circulating immune complexes (CIC). In the case of diagnosis of allergic lgE-dependent reactions, determination of s-lgE levels is needed. Also often patch and intradermal skin tests are used [2, 43]. In accordance with the European Network for Drug Allergy (ENDA) recommendations, diagnosis of allergy to drugs is based on tests done in the correct order: patch tests, intradermal tests, determining the levels of IgE specific antibodies directed against specific drugs and the provocation tests [44]. Skin tests are usually carried out when diagnosing delayed reactions to amoxicillin, erythromycin, fluoroquinolones, rifampicin, and vancomycin. These tests are particularly useful in the diagnosis of maculopapular rash, and acute generalized exanthematous rash (AGEP) [45].

The basophil activation test (BAT) is increasingly used in the diagnosis of anaphylactic reactions to drugs [46], which is based on the determination of surface basophil markers expression: CD63 and CD203c, after stimulation of antigen-specific allergen using the cytometric flow method. Basophils are easy to be stimulated and 
identified by flow cytometry, and therefore can serve as indicators of IgE-sensitization [47]. Flow cytometry method allows for simultaneous analysis of several drug allergies while only a small amount of blood is needed. It is a highly sensitive and specific method, and tests performed using the method of activation of basophils is fine in the diagnosis of obscure situations when there are discrepancies between the results of skin tests and specific IgE tests [48]. The basophil activation test is used in the diagnosis of allergy reaction to $\beta$-lactam antibiotics [49], non-steroidal anti-inflammatory drugs, and in the case of rare allergy to cyclosporine [50], heparin [51], and hyaluronidase [52].

\section{Treatment of drug allergy}

Treatment of drug allergy mainly consists of discontinuation of the suspected drug. In some cases, a typical anti-allergic or immunomodulatory treatment is needed to inhibit skin lesions or systemic reactions [53].

There are situations in which the patient requires drug therapy, to which he is allergic. In such cases, the patient can undergo desensitization. Desensitization to penicillin is the most frequent in cases of bacterial endocarditis, meningitis or syphilis of the central nervous system [20]. However, such a person is still considered to be allergic to the antibiotic. Desensitization is also used if one is allergic to cephalosporins, co-trimoxazole, metronidazole, streptomycin, vancomycin and fluoroquinolones [53].

\section{Summary}

Medications can cause many adverse reactions, both allergic and non-allergic, ranging from mild to severe skin reactions or systemic reactions. Diagnosis of allergy to drugs includes skin tests, IgE levels against specific active substances of drugs and basophil activation test for the diagnosis of anaphylaxis. Allergy treatment is usually based on the immediate cessation of the drug, and in some cases desensitization. To prevent exacerbation and relapse of severe allergic reactions and damage to health or even death in the case of anaphylaxis it is important to accurately diagnose patients with suspected allergy to drugs.

\section{Conflict of interest}

The authors declare no conflict of interest.

\section{References}

1. Bogus-Buczyńska I, Kuna P. Allergy to drugs. A difficult problem for physicians, a danger to patients. Terapia 2005; 4: 12-9.
2. Brockow K, Romano A, Blanca M, et al. General considerations for skin test procedures in the diagnosis of drug hypersensitivity. Allergy 2002; 57: 45-51.

3. Anderson JA. Allergic reactions to drugs and biological agents. JAMA 1992; 20: 2845-57.

4. Gruchalla RC, Pirmohamed M. Clinical practice. Antibiotic allergy. N Engl J Med 2006; 354: 601-9.

5. Audicana M, Bernaole G, Urrutia I, Echechipie G. Allergic reactions to betalactams: studies in a group of patients allergic to penicillin and evaluation of cross-reactivity with cephalosporin. Allergy 1994; 49: 108-13.

6. Georgy M, Wickern M, William M, Nish A. Allergy to betalactams: a survey of current practices. J Allergy Clin Immunol 1994; 94: 724-31.

7. Jäger L, Merck HF. Drug allergies. Czelej, Lublin 1997.

8. Gomes E, Cardoso MF, Praça F, et al. Self-reported drug allergy in a general adult Portuguese population. Clin Exp Allergy 2004; 34: 1597-601.

9. Borch JE, Andersen KE, Bindslev-Jensen C. The prevalence of suspected and challenge-verified penicillin allergy in a university hospital population. Basic Clin Pharmacol Toxicol 2006; 98: 357-62.

10. Finszenson-Albala F, Auzerie V, Mahe E, et al. A 6-month prospective survey of cutaneous drug reactions in a hospital setting. Br J Dermatol 2003; 149: 1018-22.

11. Rudzki E. Allergy to drugs. Czelej, Lublin 2002, 45-78.

12. Elseviers MM, Ferech M, Vander Stichele RH, et al. Antibiotic use in ambulatory care in Europe (ESAC data 1997-2002): trends, regional differences and seasonal fluctuations. Pharmacoepidemiol Drug Saf 2007; 16: 115-23.

13. Goossens H. Antibiotic consumption and link to resistance. Clin Microbiol Infect 2009; 15: 12-5.

14. Goossens H, Ferech M, Vander Stichele R, et al. Outpatient antibiotic use in Europe and association with resistance: a cross-national database study. Lancet 2005; 365: 579-87.

15. Kontarakis N, Tsiligianni IG, Papadokostakis P, et al. Antibiotic prescriptions in primary health care in a rural population in Crete, Greece. BMC Res Notes 2011; 4: 38.

16. Jedrychowski W, Gałaś A, Whyatt R, et al. The prenatal use of antibiotics and the development of allergic disease in one year old infants. A preliminary study. Int J Occup Med Environ Health 2006; 19: 70-6.

17. Kamboj S, Yousef E, McGeady S, et al. The prevalence of antibiotic skin test reactivity in a pediatric population. Allergy Asthma Proc 2011; 32: 99-105.

18. Kozyrskyj AL, Ernst P, Becker AB. Increased risk of childhood asthma from antibiotic use in early life. Chest 2007; 131: 1753-9.

19. Risnes KR, Belanger K, Murk W, et al. Antibiotic exposure by 6 months and asthma and allergy at 6 years: findings in a cohort of 1,401 US children. Am J Epidemiol 2011; 173: 310-8.

20. Czarnobilska E, Czarnobilski K, Obtułowicz A, Obtułowicz K. Allergic diseases of the elderly. Part II. Allergic diseases of the skin, allergy to medicines. Gerontol Pol 2010; 18: 57-65.

21. Janocha-Litwin J, Pazgan-Simon M, Simon K. DRESS syndrome as a complication of treatment of hepatitis C virusassociated post-inflammatory liver cirrhosis with peginterferon alpha2a and ribavirin. Postep Derm Alergol 2014; 31: 401-4.

22. Patkowski J. Allergy to drugs. In: Allergic diseases and asthma. Małolepszy J (ed). Volumed, Wroclaw 1996, 649-66.

23. Franklin N, Adkinson NF. Drug allergy. In: Middleton's allergy principles and practice. Adkinson NF, Younginger JW, Bus- 
se WW, et al. (eds.). 6th edition. Mosby Inc. Philadelphia, Pennsylvania 2003; 1679-94.

24. Korzeniowska K, Jabłecka A, Simon K. Side effects of betalactam antibiotics. Now Lek 2008; 77: 134-9.

25. Renn CN, Straff W, Dorfmüller A, et al. Amoxicillin-induced exanthema in young adults with infectious mononucleosis: demonstration of drug-specific lymphocyte reactivity. $\mathrm{Br}$ J Dermatol 2002; 147: 1166-70.

26. Mędrala W, Wolańczyk-Mędrala A, Liebhart J, et al. Studies on cross reactivity to penicillins in patients with immediate allergic reactions caused by amoxicillin. Pneumonol Alergo Pol 2002; 70: 58-63.

27. Maciejewska J, Jankowski M, Zegarska B, Czajkowski R. Stevens-Johnson syndrome/toxic epidermal necrolysis presumably induced by norfloxacin. Postep Derm Alergol 2014; 31: 194-6.

28. Herstowska M, Komorowska O, Cubała WJ, et al. Severe skin complications in patients treated with antidepressants: a literature review. Postep Derm Alergol 2014; 31: 92-7.

29. Pastuszka M, Kaszuba A. Status of combination drugs with betamethasone dipropionate and salicylic acid in the treatment of skin diseases. Postep Derm Alergol 2012; 29: 196-204.

30. Silny W, Sadowska A, Dańczak-Pazdrowska A, Polańska A. Application of tacrolimus in the treatment of skin diseases other than atopic dermatitis. Postep Derm Alergol 2011; 28: 41-5.

31. Braun-Falco O, Plewig G, Wolff HH, et al. Dermatology. Springer-Verlag, Berlin 2000.

32. Grubska-Suchanek E. Drug-induced dermatoses. Pol Merk Lek 2003; 14: 598.

33. Nacaroglu HT, Celegen M, Ozek G, et al. Acute generalized exanthematous pustulosis induced by ceftriaxone use. Postep Derm Alergol 2014; 31: 269-71.

34. Dilek N, Özkol HU, Akbaş A, et al. Cutaneous drug reactions in children: a multicentric study. Postep Derm Alergol 2014; 31: 368-71.

35. Winstroub BU, Stern RS. Drug-induced skin changes. In: Harrison's principles of internal medicine. Fauci AS, Braunwald E, Isselbacher KJ, et al. (eds.). Czelej, Lublin 2000; 461.

36. Nedorost ST, Stevens SR. Diagnosis and treatment of allergic skin disorders in the elderly. Drugs Aging 2001; 18: 827-35.

37. Jabłońska S, Chorzelski T. Drug rash. In: Diseases of the skin. Jabłońska S (ed.). PZWL, Warsaw 2002; 187: 441

38. Cleach LL, Bocquet H, Roujeau JC. Reactions and interactions of some commonly used systemic drugs in dermatology. Dermatol Clin 1998; 16: 421-9.

39. Woźniacka A, Sysa-Jędrzejowska A, Robak E, Żak-Prelich M. Dermal drug reactions. Prz Lek 2002; 59: 183.

40. Lecewicz-Toruń B. Drug reactions. Dermatology. Medipress 1997; 4: 13.

41. Żebrowski MR, Machlańska A, Waszczykowska E, Żebrowska A. Cutaneous drug reactions induced by the cardiological medicines. Forum Kardiol 2005; 10: 7-15.

42. Beylot C, Doutre MS, Beylot-Barry M. Acute generalized exanthematous pustulosis. Semin Cutan Med Surg 1996; 4: 244-9.

43. Jenerowicz D. Diagnostic difficulties in drug adverse reactions. Postep Derm Alergol 2005; 22: 233-8.

44. Torres MJ, Blanca M, Fernandez J, et al. Diagnosis of immediate allergic reactions to beta-lactam antibiotics. Allergy 2003; 58: 961-72.

45. Barbaud A. Skin testing in delayed reactions to drugs. Immunol Allergy Clin North Am 2009; 29: 517-35.
46. Hausmann OV, Gentinetta T, Bridts CH, Ebo DG. The basophil activation test in immediate-type drug allergy. Immunol Allergy Clin North Am 2009; 29: 555-66.

47. Porębski G, Czarnobliska E, Obtułowicz K. Current approach in studies on drug hypersensitivity reactions. Alergologia Immunologia 2010; 7: 44-6.

48. Potapińska O, Demkow U, Wąsik M. Flow cytometric basophils activation test as a method of allergy diagnosis. Pneumonol Alergol Pol 2009; 77: 152-8.

49. Ben Said B, Berard F, Bienvenu J, et al. Usefulness of basophil activation tests for the diagnosis of IgE-mediated allergy to quinolones. Allergy 2010; 65: 535-6.

50. Ebo DG, Piel GC, Conraads V, Stevens WJ. IgE-mediated anaphylaxis after first intervenous infusion of cyclosporine. Ann Aller Asthma Immunol 2001; 87: 243-5.

51. Ebo DG, Haine SE, Hagendorens MM, et al. Hypersensitivity to nadroparin calcium: case report and review of the literature. Clin Drug Invest 2004; 24: 421-6.

52. Ebo DG, Goossens S, Opsomer F, et al. Flow-assisted diagnosis of anaphylaxis to hyaluronidase. Allergy 2005; 60: 1333-4.

53. Thong BYH. Update on the management of antibiotic allergy. Allergy Asthma Immunol Res 2010; 2: 77-86. 